\title{
Prevalence of metabolic syndrome in the Gulf Cooperation Council countries: meta-analysis of cross-sectional studies
}

\author{
Seungmin Shin' ${ }^{1}$ Haemi Jee ${ }^{2, *}$ \\ 'Physical Education Department, King Fahd University of Petroleum \& Minerals, Dhahran, Saudi Arabia \\ 2Department of Physical Therapy, Namseoul University, Cheonan, Korea
}

Metabolic syndrome is a collection of health-related conditions that lead to serious health condition. An individual with metabolic syndrome may acquire greater risk for adult-onset complications such as cardiovascular or neurological disorders. The aim of this study was to review and provide the prevalence of metabolic syndrome in Gulf Cooperation Council countries (GCC). Literature searches were performed on PubMed, Google scholar, and Web of Science Core Collection for English-language articles along with national studies. The following search terms were used during search: "prevalence of metabolic syndrome in GCC," "prevalence of metabolic syndrome in middle east," "prevalence of metabolic syndrome in Arab," and "prevalence of metabolic syndrome name of country." Thirty-seven studies were selected for final review out of 132 studies. The weighted pooled prevalence of metabolic syndrome was $27.3 \%$ with high heterogeneity $\left(l^{2}=98.94 \%\right.$; Cochran Q-test $P<0.01)$. The results showed comparatively high and rising rate of metabolic syndrome in the GCC area. Preventative strategy should be considered to reduce the risk of morbidity or mortality related to metabolic syndrome.

Keywords: Metabolic syndrome, Prevalence, Gulf Cooperation Council, Meta-analysis

\section{INTRODUCTION}

The metabolic syndrome has been known to acquire by sedentary lifestyle and calorie rich eating habit. Various metabolic factors may lead to development of life strengthening diseases such as cardiovascular disease, type 2 diabetes, dyslipidemia, and hypertension (Ranasinghe et al., 2017). Although adult-onset diseases may solely occur without the metabolic factors, the risk for the co-occurrence has been known to increase by several folds with the existing metabolic factors (Mente et al., 2010). The most common definitions used to define metabolic syndrome were reported by the World Health Organization (WHO), European Group for Study of Insulin Resistance, National Cholesterol Education Program Adult Treatment Panel III (NCEP ATP III), International Diabetes Federation (IDF), and Joint Interim Societies (JIS). The metabolic syndrome was defined by basically similar components that included terms. For example, WHO used components such as impaired fasting glucose, impaired glucose tolerance, homeostatic model assessment for insulin resistance, obesity, dyslipidemia, hypertension, waist circumference, and blood pressure as criteria. The NCEP ATP III used components such as fasting triglyceride, fasting high-density lipoprotein, fasting blood glucose as criteria for prevalence of metabolic syndrome (Huang, 2009).

The member states of the Gulf Cooperation Council (GCC) include Bahrain, Kuwait, Oman, Qatar, Saudi Arabia, and the United Arab Emirates. Recently, the prevalence of the type II diabetes mellitus and related adult-onset disorders have reported to be high in the GCC countries. Several publications reported that four out of six countries of the GCC countries are among the top 10 countries with the greatest prevalence rate for adult-onset type 2 dia-
${ }^{*}$ Corresponding author: Haemi Jee (iD https://orcid.org/0000-0002-9066-1472 Department of Physical Therapy, Namseoul University, 91 Daehak-ro, Seobuk-gu, Cheonan 31020, Korea

E-mail:wlgpal9@gmail.com

Received: December 31, 2019 / Accepted: February 5, 2020
This is an Open Access article distributed under the terms of the Creative Commons Attribution Non-Commercial License (https://creativecommons.org/licenses/by-nc/4.0/) which permits unrestricted non-commercial use, distribution, and reproduction in any medium, provided the original work is properly cited. 
betes and cardiovascular diseases (Al-Lawati et al., 2008; Kamran et al., 2007; Ranasinghe et al., 2017). The rapidly increasing rate of the adult-onset chronic complications such as type 2 diabetes and cardiovascular diseases have been related to the changes in the environment and lifestyle that lead to sedentary lifestyle and consumption of food high in calorie (Malik and Razig, 2008). Despite various studies on the prevalence of metabolic syndrome in the GCC countries, the overall report on the metabolic syndrome in the GCC countries is scarce. Therefore, this report was conducted to provide the evidence-based prevalence rate of metabolic syndrome in the GCC area through meta-analysis. Providing evidencebased prevalence rate of the metabolic syndrome in the GCC area could contribute fundamental foundation for developing scientifically supportive evidence for the metabolic syndrome prevention campaign.

\section{MATERIALS AND METHODS}

This study is a systemic review prepared by the meta-analysis based on the guidelines provided by the PRISMA (Preferred Reporting Items for Systematic Review and Meta-Analysis protocol) (Moher et al., 2010; Shamseer et al., 2015).

\section{Data sources and search phrases}

In order to obtain evidence-based study results on the prevalence rate for the metabolic syndrome, electronic literature searches were conducted on the web-based database sites such as the PubMed database, Google Scholar, and Web of Science collection. Only the English-language research articles with the nation-wide or population-based subjects were gathered for this study. The initial data collection was conducted without filtering for time. Specific search terms or phrases were used to find the articles. The search phrases included "prevalence of metabolic syndrome in middle east," "prevalence of metabolic syndrome in Arab," "prevalence of metabolic syndrome," "name of country," and "metabolic syndrome."

\section{Article selection procedure}

After the initial gathering procedure, the selected articles were considered for inclusion based on the following inclusion and exclusion criteria. This study used broad inclusion criteria to provide comprehensive systemic reviews of the topic.

First, the articles were considered for inclusion if the articles were original research studies and reported on the prevalence rate for the metabolic syndrome. There were no restrictions on the study type unless the articles are review articles. Cohort and cross-sectional studies were also included. Geographic regions

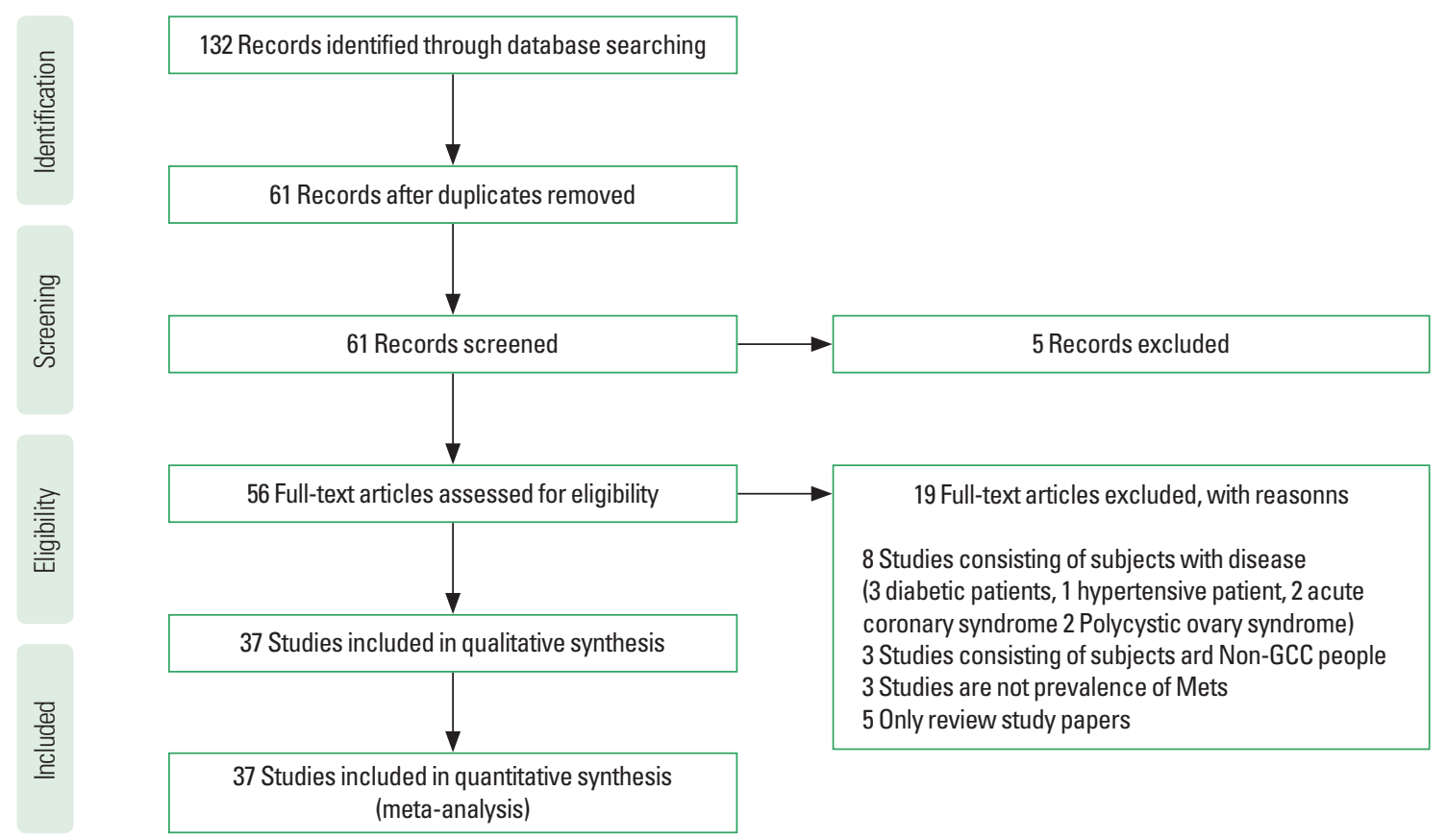

Fig. 1. PRISMA (Preferred Reporting Items for Systematic Review and Meta-Analysis protocol) diagram for the systematic review of the metabolic syndrome prevalence rates in the Gulf Cooperation Council counties population. 
such as urban or rural regions were not excluding criteria. The studies on specific clinical complications such as diabetes, acute coronary syndrome, ovary syndrome, or hypertension were excluded from the study. In addition, the studies that did not deal with the prevalence of metabolic syndrome as the major factor were also not included in this study. In the initial selection phase, the studies were selected based on the key terms and phrases. During the second phase, the studies were reviewed for the title and abstract for exclusion. Finally, initially selected articles were screen and reviewed based on the full text for the final exclusion and inclusion process.

\section{Data extraction}

Information on the authors, year of publication, country of origin, sample size, gender and age of the subjects, and study design (case-control, cross-sectional or prospective cohort), metabolic syndrome identification criteria, prevalence of metabolic syndrome, and adjustment variables were obtained from the selected articles. Regarding the considerable factors and expected heterogeneity.

The random-effect model was applied for the analysis of data to obtain the expected heterogeneity and the considerable factors. The Cochran Q-test was utilized to estimate the heterogeneity between the selected studies.

\section{Data synthesis and statistical analysis}

The management and edition of data, estimation of standard error, and pooled mean effect size were estimated using Comprehensive Meta-Analysis Software (CMA) ver. 2.0 (Biostat, Englewood, NJ, USA). The pooled estimate of the prevalence rates was determined by the definitions on the metabolic syndrome provided by the ATP III, IDF, WHO, and JIS. Finally, the weighted average prevalence rates with $95 \%$ confidence interval (CI) for the selected studies were obtained by calculating the fixed effects and random effects of the meta-analysis.

\section{RESULTS}

One hundred thirty-two articles were retrieved on the prevalence or metabolic syndrome in the GCC countries through extensive search process online. After through inclusion and exclusion procedures, duplications and irrelevant articles were excluded. After reviewing the title and abstracts, 56 articles were selected for full-text screening. After the full article reviewing, seven articles were excluded due to chronic diseases, three articles were excluded since they were conducted on the subjects that were not of the GCC countries, and five were excluded for being review articles. Therefore, among 132 articles, 37 articles were selected as the final articles for the systematic review. The selection processes for the articles are shown in Fig. 1.

Within 37 articles, 53 different studies were identified and included for the review. Among 53 studies, 19 were published before the year 2009 and 35 were published in the year 2010 or later. Different criteria were used to diagnose metabolic syndrome in the selected studies. Fifteen studies used the criteria proposed by the NCEP ATP III for diagnosing the metabolic syndrome. Eight studies used the criteria by the IDF and 13 studies used the criteria by both NCEP ATP III and IDF. One study used the criteria by NCEP ATP III and WHO and another study used the criteria by NCEP ATP III, IDF, and JIS (Table 1). The metabolic syndrome prevalence rate is also shown as a forest plot for in Fig. 2.

Tables 2 and 3 show the pooled estimates for the prevalence rates of the metabolic syndrome in each country and the overall pooled estimated, respectively. The prevalence rates of the metabolic syndrome in Oman was 0.25 (95\% CI, 0.19-0.31), UAE was 0.39 (95\% CI, 0.34-0.42), Saudi was 0.28 (95\% CI, 0.240.33 ), Kuwait was 0.22 (95\% CI, 0.17-0.27), and Qatar was 0.26 (95\% CI, 0.18-0.37). Moreover, the pooled prevalence rates of the metabolic syndrome were estimated for the subgroups of studies (Table 4). The random pooled samples of the studies reported before 2009 and after 2010 showed the metabolic syndrome preva-

Table 1. Characteristics of the reviewed studies

\begin{tabular}{|c|c|c|c|c|c|c|c|}
\hline Country & Study & Type of study & Published year & $\begin{array}{l}\text { Sample size } \\
\text { (person) }\end{array}$ & Metsdefinition & $\begin{array}{c}\text { Mets prevalence } \\
\text { rate }(\%)\end{array}$ & Adjustments \\
\hline \multirow[t]{6}{*}{ Oman } & Al-Lawati et al. & Cross-sectional & 2003 & 1,419 & ATP III & 17.0 (crude) & \\
\hline & & & & & & 21.0 (adjust) & Age \\
\hline & Al-Shafaee et al. & Cross-sectional & 2008 & 281 & ATP III & 45.9 & \\
\hline & El-Aty et al. & Cross-sectional & 2014 & 3,137 & ATP III & 23.6 & Age \\
\hline & Al-barwani et al. & Cross-sectional & 2008 & 392 & IDF & 28.0 & \\
\hline & & & & & ATP III & 21.0 & \\
\hline
\end{tabular}

(Continued to the next page) 
Table 1. Continued

\begin{tabular}{|c|c|c|c|c|c|c|c|}
\hline Country & Study & Type of study & Published year & $\begin{array}{l}\text { Sample size } \\
\text { (person) }\end{array}$ & Metsdefinition & $\begin{array}{c}\text { Mets prevalence } \\
\text { rate }(\%)\end{array}$ & Adjustments \\
\hline \multirow[t]{5}{*}{ UAE } & Khthir and Espina & Cross-sectional & 2014 & 575 & ATP III & 22.0 & \\
\hline & Hajat and Shather & Cross-sectional & 2012 & 760 & IDF & 48.7 & \\
\hline & & & & & ATP III & 50.3 & \\
\hline & Malik and Razig & Cross-sectional & 2008 & 4,097 & IDF & 40.5 & \\
\hline & & & & & ATP III & 39.6 & \\
\hline \multirow[t]{24}{*}{ Saudi } & Al-Sarraj et al. & Cross-sectional & 2008 & 309 & ATP III & 25.2 & \\
\hline & Al-Sarraj et al. & Cross-sectional (obesity) & 2010 & 227 & ATP III & 40.4 & \\
\hline & Haroun et al. & Cross-sectional & 2018 & 591 & IDF & 4.9 & \\
\hline & Rouzi and Ardawi & Cross-sectional & 2009 & 580 & ATP III & 33.4 & \\
\hline & Bahijri et al. & Cross-sectional & 2013 & 233 & IDF & 18.9 & \\
\hline & & & & & ATP III & 16.7 & \\
\hline & Al-Qahtani and Imtiaz & Cross-sectional & 2005 & 1,079 & ATP III & 20.0 & Age \\
\hline & Aljohani & Cross-sectional & 2014 & 4,406 & IDF & 28.3 & \\
\hline & Al-Nozha et al. & Cross-sectional & 2005 & 17,293 & ATP III & 41.4 (crude) & \\
\hline & & & & & & 39.3 (adjust) & Age \\
\hline & Al-Qahtani et al. & Cross-sectional & 2006 & 2,577 & IDF & 16.1 & Age \\
\hline & & & & & ATP III & 13.6 & Age \\
\hline & Barrimah et al. & Cross-sectional & 2011 & 560 & ATP III & 31.4 & \\
\hline & Taha et al. & Cross-sectional & 2009 & 37 & ATP III & 29.7 & \\
\hline & Alzahrani et al. & Cross-sectional & 2012 & 600 & ATP III & 21.0 & \\
\hline & Al-Agha et al. & Cross-sectional & 2012 & 387 & ATP III & 14.3 & \\
\hline & Al-Daghri et al. & Cross-sectional & 2013 & 185 & IDF & 39.0 & \\
\hline & AboGazalah and AIReshidi & Cross-sectional & 2016 & 250 & ATP III & 36.0 & \\
\hline & & & & & WHO & 39.1 & \\
\hline & Alswat et al. & Cross-sectional & 2016 & 313 & IDF & 38.4 & \\
\hline & Aljabri et al. & Cross-sectional (obesity) & $2018 a$ & 1,526 & IDF & 69.5 & \\
\hline & Al-Rubeaan et al. & Cross-sectional & 2018 & 12,126 & ATP III/IDF & 39.8 & \\
\hline & Aljabri et al. & Cross-sectional & $2018 b$ & 2,810 & IDF & 64.6 & \\
\hline & Saeed & Cross-sectional & 2019 & $1,354 a$ & IDF & 12.0 & \\
\hline \multirow[t]{12}{*}{ Kuwait } & Badr et al. & Cross-sectional & 2007 & 434 & ATP III & 18.0 & \\
\hline & Al-Isa et al. & Cross-sectional & 2010 & 431 & IDF & 14.8 & \\
\hline & Al Zenki et al. & Cross-sectional & 2012 & 1,830 & $\begin{array}{l}\text { IDF/ATP III } \\
\quad(W C>102 / 85 \mathrm{~cm})\end{array}$ & 36.1 & \\
\hline & Al-Isa & Cross-sectional & 2013 & 303 & IDF & 11.7 & \\
\hline & & & & & ATP III (modified) & 9.8 & \\
\hline & Roshdy & Cross-sectional & 2011 & 153 & JIS & 28.1 & \\
\hline & & & & & IDF & 26.1 & \\
\hline & & & & & ATP III & 18.3 & \\
\hline & Al Rashdan and Al Nesef & Cross-sectional & 2010 & 2,280 & ATP III & 24.8 & \\
\hline & & & & & IDF & 36.2 & \\
\hline & Boodai et al. & Cross-sectional & 2014 & 80 & ATP III & 30.0 & \\
\hline & & & & & IDF & 21.3 & \\
\hline \multirow[t]{6}{*}{ Oatar } & Bener et al. & Cross-sectional & 2009 & 1,024 & ATP $\|$ & 26.5 & \\
\hline & & & & & IDF & 33.7 & \\
\hline & Bener et al. & Cross-sectional & 2014 & 1,552 & ATP III & 10.3 & \\
\hline & Al-Thani et al. & Cross-sectional & 2016 & 2,496 & IDF/ATP I|| & 37.0 & \\
\hline & Hammoudeh et al. & Cross-sectional & 2018 & 226 & ATP III & 27.4 & \\
\hline & & & & & $\mathrm{IDF}$ & 32.7 & \\
\hline
\end{tabular}

ATP III, Adult Treatment Panel III; IDF, International Diabetes Foundation; WHO, World Health Organization; JIS, Joint Interim Societies; WC, waist circumference. 
Model Study name

Jawada Al Lawati (oman 2003) adjust Jawada Al Lawati (oman 2003) crude Al-Shafaee (oman 2008)

Mahmoud Ahd El-Aty (oman 2014)

Al-barwani, S. A (oman 2008) ATP

Al-barwani, S. A (oman 2008) IDF

Rodhan Khathir (UAE 2014)

Cother Hajat (UAE 2012) ATP

Cother Hajat (UAE 2012) IDF

Malik M (UAE 2008) ATP

Malik M (UAE 2008) IDF

T Al-Sarraj (saudi 2008)

T Al-Sarraj (saudi 2010)

D Haroun (saudi 2018)

A Rouzi (saudi 2009)

Suhadm Bahiji (saudi 2012) ATP III

Suhadm Bahiji (saudi 2012) IDF

Dhafer A. AlQahteni (saudi 2005)

Najij Aljohani (saudi 2014)

Mansour M AL Nozha (saudi 2005) adjust

Mansour M AL Nozha (saudi 2005) crude

Al-Qahtani, D. A. (saudi 2006) ATP III

Al-Qahtani, D. A. (saudi 2006) IDF

I Barrimah (saudi 2009)

D Taha (saudi 2009)

AM Alzahrani (saudi 2012)

A Al-Agha (saudi 2013)

N Al-Daghri (saudi 2013)

FN AboGazalah (saudi 2014) ATP

FN AboGazalah (saudi 2014) WHO

M Khaled Alswat (saudi 2016)

KS Aljabri (saudi 2018) obesity

K Al-Rubeaan (saudi 2018)

KS Aljabri (saudi 2018)

AA Saeed (saudi 2019)

Hanan E (kuwait 2007)

AL-Isa (kuwait 2010)

Sameer Al Zenki (kuwait 2012)

Abduwahab Al-Isa(kuwait 2013) ATP

Abduwahab Al-Isa(kuwait 2013) IDF

Reda Roshdy (kuwait 2011) ATP

Reda Roshdy (kuwait 2011) IDF

Reda Roshdy (kuwait 2011) JIS

I Al Rashdan (kuwait 2010) ATP

I Al Rashdan (kuwait 2010) IDF

SA Boodai (kuwait 2014) IDF

SA Boodai (kuwait 2014) ATP

Bener Abdolbari (Qatar 2009) ATP

Bener Abdolbari (Catar 2009) IDF

EA Nasralla (Qatar 2014) ATP

EA Nasralla (Qatar 2014) IDF

MH Al-Thani (Qatar 2016)

$S$ Hammoudeh (Qatar 2018) ATP

Random
Statistics for each study

$\begin{array}{ccc}\begin{array}{c}\text { Event } \\ \text { rate }\end{array} & \text { Lower } & \text { Upper } \\ \text { limit } & \text { limit }\end{array}$

$0.210 \quad 0.190 \quad 0.232$

0.170

$\begin{array}{lll}0.459 & 0.402 & 0.518\end{array}$

$\begin{array}{lll}0.236 & 0.221 & 0.251\end{array}$

$\begin{array}{lll}0.209 & 0.172 & 0.252\end{array}$

$\begin{array}{lll}0.281 & 0.238 & 0.327\end{array}$

$\begin{array}{lll}0.221 & 0.189 & 0.257\end{array}$

$\begin{array}{lll}0.503 & 0.467 & 0.538\end{array}$

$\begin{array}{lll}0.487 & 0.451 & 0.522\end{array}$

$0.396 \quad 0.381 \quad 0.411$

$\begin{array}{lll}0.405 & 0.390 & 0.420\end{array}$

$\begin{array}{lll}0.252 & 0.207 & 0.304\end{array}$

$\begin{array}{lll}0.405 & 0.343 & 0.470\end{array}$

$\begin{array}{lll}0.049 & 0.034 & 0.070\end{array}$

$\begin{array}{lll}0.334 & 0.297 & 0.374\end{array}$

$\begin{array}{lll}0.167 & 0.125 & 0.221\end{array}$

$\begin{array}{lll}0.189 & 0.144 & 0.244\end{array}$

$\begin{array}{lll}0.208 & 0.184 & 0.233\end{array}$

$\begin{array}{lll}0.283 & 0.270 & 0.297\end{array}$

$\begin{array}{lll}0.393 & 0.386 & 0.400\end{array}$

$\begin{array}{lll}0.414 & 0.407 & 0.421\end{array}$

$\begin{array}{lll}0.136 & 0.123 & 0.150\end{array}$

$\begin{array}{lll}0.161 & 0.147 & 0.176\end{array}$

$\begin{array}{lll}0.314 & 0.277 & 0.354\end{array}$

$\begin{array}{lll}0.297 & 0.173 & 0.461\end{array}$

$\begin{array}{lll}0.210 & 0.179 & 0.244\end{array}$

$\begin{array}{lll}0.142 & 0.111 & 0.181\end{array}$

$\begin{array}{lll}0.389 & 0.322 & 0.461\end{array}$

$\begin{array}{lll}0.360 & 0.303 & 0.421\end{array}$

$\begin{array}{lll}0.392 & 0.333 & 0.454\end{array}$

$\begin{array}{lll}0.383 & 0.331 & 0.438\end{array}$

$\begin{array}{lll}0.695 & 0.671 & 0.717\end{array}$

$\begin{array}{lll}0.398 & 0.389 & 0.407\end{array}$

$0.646 \quad 0.628 \quad 0.663$

$\begin{array}{lll}0.118 & 0.102 & 0.136\end{array}$

$\begin{array}{lll}0.180 & 0.146 & 0.219\end{array}$

$\begin{array}{lll}0.148 & 0.118 & 0.185\end{array}$

$\begin{array}{lll}0.361 & 0.339 & 0.383\end{array}$

$\begin{array}{lll}0.099 & 0.070 & 0.138\end{array}$

$\begin{array}{lll}0.119 & 0.087 & 0.160\end{array}$

$\begin{array}{lll}0.183 & 0.129 & 0.252\end{array}$

$\begin{array}{lll}0.261 & 0.198 & 0.337\end{array}$

$0.281 \quad 0.216 \quad 0.357$

$\begin{array}{lll}0.362 & 0.342 & 0.382\end{array}$

$\begin{array}{lll}0.248 & 0.231 & 0.266\end{array}$

$\begin{array}{lll}0.300 & 0.210 & 0.409\end{array}$

$\begin{array}{lll}0.212 & 0.136 & 0.316\end{array}$

$\begin{array}{lll}0.265 & 0.239 & 0.293\end{array}$

$\begin{array}{lll}0.337 & 0.309 & 0.366\end{array}$

$\begin{array}{lll}0.242 & 0.207 & 0.282\end{array}$

$\begin{array}{lll}0.271 & 0.233 & 0.311\end{array}$

$\begin{array}{lll}0.370 & 0.351 & 0.389\end{array}$

$\begin{array}{lll}0.274 & 0.220 & 0.336\end{array}$

$\begin{array}{lll}0.327 & 0.269 & 0.391\end{array}$

$\begin{array}{lll}0.277 & 0.250 & 0.306\end{array}$
Event rate and $95 \% \mathrm{CI}$
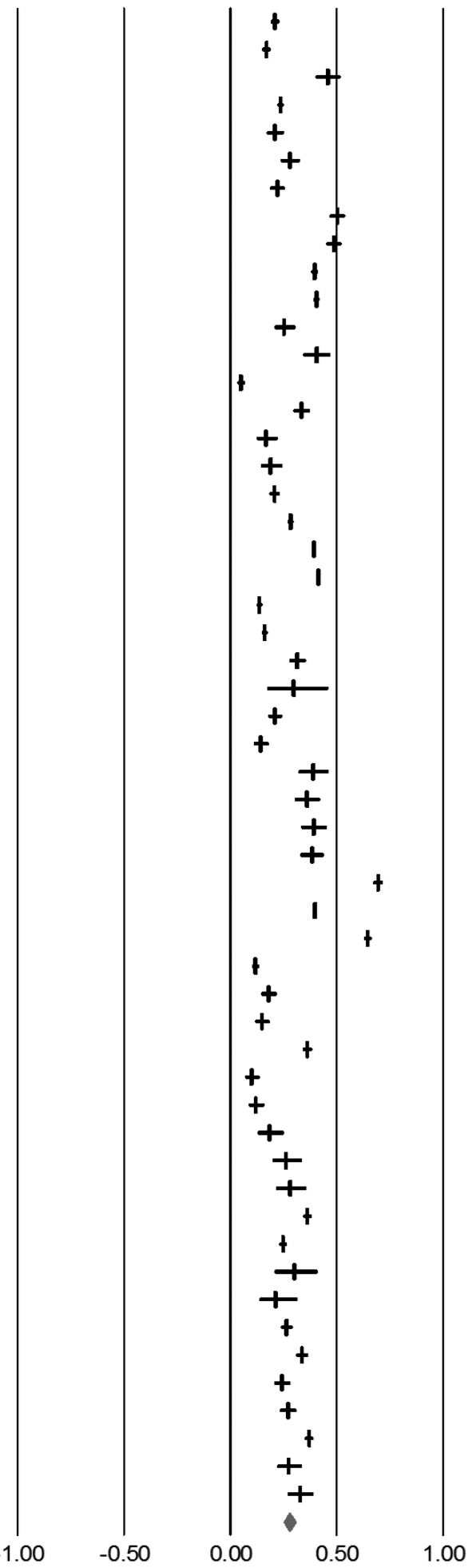

Fig. 2. Forest plot for the metabolic syndrome prevalence rate of Gulf Cooperation Council counties. 
Table 2. Pooled estimations of the metabolic syndrome prevalence rate by country

\begin{tabular}{lccccc}
\hline Country & $\begin{array}{c}\text { No. of } \\
\text { studies }\end{array}$ & $\begin{array}{c}\text { Sample } \\
\text { size }\end{array}$ & $\begin{array}{c}\text { Pooled } \\
\text { prevalence }\end{array}$ & $\begin{array}{c}95 \% \text { Confidence } \\
\text { interval }\end{array}$ & $P$-value \\
\hline Oman & 6 & 7,040 & 0.25 & $0.19-0.31$ & $<0.01^{*}$ \\
UAE & 5 & 10,289 & 0.39 & $0.34-0.45$ & $<0.01^{*}$ \\
Saudi & 24 & 67,796 & 0.28 & $0.24-0.33$ & $<0.01^{*}$ \\
Kuwait & 12 & 8,480 & 0.22 & $0.17-0.27$ & $<0.01^{*}$ \\
Oatar & 7 & 5,994 & 0.29 & $0.25-0.34$ & $<0.01^{*}$ \\
\hline
\end{tabular}

${ }^{*} P<0.05$.
Table 3. Overall pooled estimation of the metabolic syndrome prevalence rate

\begin{tabular}{lccccc} 
Model & $\begin{array}{c}\text { No. of } \\
\text { studies }\end{array}$ & $\begin{array}{c}\text { Sample } \\
\text { size }\end{array}$ & $\begin{array}{c}\text { Pooled } \\
\text { prevalence }\end{array}$ & $\begin{array}{c}95 \% \text { Confidence } \\
\text { interval }\end{array}$ & $P$-value \\
\hline Fixed & 54 & 99,599 & 0.37 & $0.36-0.37$ & $<0.01^{*}$ \\
Random & 54 & 99,599 & 0.28 & $0.25-0.31$ & $<0.01^{*}$ \\
\hline
\end{tabular}

${ }^{*} P<0.05$

Table 4. Summary of the main results of the reviewed articles

\begin{tabular}{|c|c|c|c|c|c|}
\hline Variable & No. of studies & Sample size & Effect sizes (95\% Cl) & Effect sizes (95\% Cl) & $P$-value \\
\hline & & & Fixed pooled prevalence & Random pooled prevalence & \\
\hline \multicolumn{6}{|l|}{ Year of study } \\
\hline 2003-2009 & 19 & 56,884 & $0.37(0.36-0.37)$ & $0.28(0.24-0.32)$ & $<0.01^{*}$ \\
\hline 2009-2019 & 35 & 42,715 & $0.37(0.36-0.37)$ & $0.28(0.24-0.32)$ & $<0.01^{*}$ \\
\hline \multicolumn{6}{|l|}{ Diagnostic criteria } \\
\hline ATP III & 29 & 56,815 & $0.36(0.35-0.36)$ & $0.25(0.22-0.28)$ & $<0.01^{*}$ \\
\hline IDF & 20 & 25,929 & $0.37(0.36-0.37)$ & $0.30(0.23-0.38)$ & $<0.01 *$ \\
\hline ATP III/IDF & 3 & 16,452 & $0.39(0.38-0.40)$ & $0.38(0.35-0.40)$ & $<0.01^{*}$ \\
\hline JIS & 1 & 153 & $0.28(0.22-0.36)$ & $0.28(0.22-0.36)$ & $<0.01^{*}$ \\
\hline WHO & 1 & 250 & $0.39(0.33-0.45)$ & $0.39(0.33-0.45)$ & $<0.01^{*}$ \\
\hline \multicolumn{6}{|l|}{ Adjustment } \\
\hline Age and sex adjusted & 6 & 31,409 & $0.33(0.32-0.33)$ & $0.23(0.16-0.32)$ & $<0.01^{*}$ \\
\hline Nonadjusted & 48 & 36,997 & $0.38(0.38-0.39)$ & $0.28(0.26-0.32)$ & $<0.01^{*}$ \\
\hline
\end{tabular}

Cl, confidence interval; ATP III, Adult Treatment Panel III; IDF, International Diabetes Foundation; JIS, Joint Interim Societies; WHO, World Health Organization. ${ }^{*} P<0.05$.

lence rates of 0.28 (95\% CI, 0.24-0.32) and 0.27 (95\% CI, $0.23-$ 0.32 ), respectively.

Twenty-nine studies used the ATP III definition and the prevalence rate in the random pooled estimate was 0.25 (95\% CI, $0.22-0.28)$. Ninety studies used the IDF definition and prevalence rate in the random pooled estimate was 0.28 (95\% CI, 0.21-0.36). Three studies used both the ATP III and IDF and their prevalence rate in the random pooled estimate was 0.38 (95\% CI, 0.35-0.40). One study used the JIS definition and its prevalence rate in the random pooled estimate was 0.28 (95\% CI, $0.22-0.36)$. Finally, the last one study used the WHO definition and the prevalence rate in the random pooled estimate was 0.39 (95\% CI, 0.39-0.45).

Regarding the effects of the adjustment on the random pooled estimates, six adjusted studies showed pooled for prevalence rate by the random effect of 0.28 (95\% CI, 0.16-0.32). Forty-seven nonadjusted studies showed pooled prevalence by the random effect of 0.28 (95\% CI, 0.25-0.31).

\section{DISCUSSION}

This study was conducted to observe the prevalence rate of metabolic syndrome in the GCC countries. In this meta-analysis review, 54 studies and 99,599 subjects were analyzed for the prevalence of metabolic syndrome. Overall, the pooled estimate of the metabolic syndrome prevalence rate in GCC was 0.28 (95\% CI, $0.25-0.31$ ). Such metabolic syndrome prevalence rate in the GCC region was greater than that of the other regions such as Latin American, Europe, Africa, and Asia. That is, the observed prevalence rate of the metabolic syndrome in the GCC countries such as was observably higher than other countries worldwide. For example, a systematic review of the countries in the Latin America region showed the metabolic syndrome prevalence rate of $24.9 \%$ with the ATP III's metabolic syndrome definition (Márquez-Sandoval et al., 2011). A combined prospective cohort study on the prevalence rate of the metabolic syndrome reported of $15.0 \%$ in Europe with the WHO's metabolic syndrome definition (Hu et 
al., 2004).

The prevalence rates of metabolic syndrome in the Sub-Saharan African regions range from $0 \%$ to $7.3 \%$ (Fezeu et al., 2007). A systematic review that reported the prevalence rates in the Asia-pacific region was $11.9 \%$ and $49.0 \%$ according to the definitions by ATP III and modified ATP III, respectively (Ranasinghe et al., 2017). On the other hand, the prevalence rates reported by the national survey in the United States were 35\% and 39\% according to the definitions by the ATP III and IDF, respectively (Ford, 2005). Therefore, the prevalence rate for the metabolic syndrome was high in comparison to some of the regions such as Africa or Asia while still lower than the regions such as the United States.

Over the past few decades, many of the GCC countries have experienced rapid wealth and corresponding urbanization. Such changes have led to a sedentary lifestyle by the general population due to rapid increase in the usage of motored vehicles for commuting. In addition, the working environment and facilities have changed to promote reduction in physical activity. The dietary patterns also changed in association with the environmental changes to promote inactivity and corresponding adult-onset diseases (Alzeidan et al., 2018). Conditions such as the infrastructure of the urban areas with scarce sidewalks or parks, hot arid climate, and conservative social culture restrict physical activity in the Gulf region (Alzeidan et al., 2018).

Although a vast amount of databases and articles were reviewed with detailed inclusion and exclusion criteria for the final selection limitations exist. Since a significant amount of regional reports were prepared in the native language, non-English articles could not be included in this study. The local studies that represent the regional information may provide more detailed input on the prevalence rate.

However, this is the first meta-analysis report on the prevalence ate of the metabolic syndrome in the GCC countries to our knowledge. This report may provide supportive information to prepare for the measures to intervene to prevent and control the onset of metabolic syndrome in the GCC region. It may assist to manage the morbidity and mortality rate related to adult-onset complications.

\section{CONFLICT OF INTEREST}

No potential conflict of interest relevant to this article was reported.

\section{REFERENCES}

AboGazalah FN, AlReshidi FS. The prevalence of metabolic syndrome among chronic disease patients in Alwazarat health center at Prince Sultan Military Medical City, Riyadh, Saudi Arabia, 2014. Int J Med Sci Public Health 2016;5:125-134.

Al-Agha A, Ocheltree A, Shata N. Prevalence of hyperinsulinism, type 2 diabetes mellitus and metabolic syndrome among Saudi overweight and obese pediatric patients. Minerva Pediatr 2012;64:623-631.

Al-barwani SA, Bayoumi RA, Jaju D, Al-Yahyaee SA, Al-Hadabi S, LopezAlvarenga JC, Comuzzie AG, Hassan MO. Differing definition-based prevalence of metabolic syndrome in the women of Oman family study: a function of multiparity. Metab Syndr Relat Disord 2008;6:197202.

Al-Daghri NM, Khan N, Alkharfy KM, Al-Attas OS, Alokail MS, Alfawaz HA, Alothman A, Vanhoutte PM. Selected dietary nutrients and the prevalence of metabolic syndrome in adult males and females in Saudi Arabia: a pilot study. Nutrients 2013;5:4587-4604.

Al-Isa A. Prevalence of metabolic syndrome (MetS) among male Kuwaiti adolescents aged 10-19 years. Health 2013;5:938-942.

Al-Isa A, Akanji AO, Thalib L. Prevalence of the metabolic syndrome among female Kuwaiti adolescents using two different criteria. Br J Nutr 2010;103:77-81.

Al-Lawati JA, Mabry R, Mohammed AJ. Addressing the threat of chronic diseases in Oman. Prev Chronic Dis 2008;5:A99.

Al-Lawati JA, Mohammed AJ, Al-Hinai HQ, Jousilahti P. Prevalence of the metabolic syndrome among Omani adults. Diabetes Care 2003;26: 1781-1785.

Al-Nozha M, Al-Khadra A, Arafah MR, Al-Maatouq MA, Khalil MZ, Khan NB, Al-Mazrou YY, Al-Marzouki K, Al-Harthi SS, Abdullah M, AlShahid MS, Al-Mobeireek A, Nouh MS. Metabolic syndrome in Saudi Arabia. Saudi Med J 2005;26:1918-1925.

Al-Qahtani DA, Imtiaz ML. Prevalence of metabolic syndrome in Saudi adult soldiers. Saudi Med J 2005;26:1360-1366.

Al-Qahtani DA, Imtiaz ML, Saad OS, Hussein NM. A comparison of the prevalence of metabolic syndrome in saudi adult females using two definitions. Metab Syndr Relat Disord 2006;4:204-214.

Al Rashdan I, Al Nesef Y. Prevalence of overweight, obesity, and metabolic syndrome among adult Kuwaitis: results from communitybased national survey. Angiology 2010;61:42-48.

Al-Rubeaan K, Bawazeer N, Al Farsi Y, Youssef AM, Al-Yahya AA, AlQumaidi H, Al-Malki BM, Naji KA, Al-Shehri K, Al Rumaih FI. Prevalence of metabolic syndrome in Saudi Arabia - a cross sectional study. BMC Endocr Disord 2018;18:16.

Al-Sarraj T, Saadi H, Volek JS, Fernandez ML. Prevalence of the metabolic 
syndrome in the United Arab Emirates. FASEB J 2008;22:1083-1110.

Al-Sarraj T, Saadi H, Volek JS, Fernandez ML. Metabolic syndrome prevalence, dietary intake, and cardiovascular risk profile among overweight and obese adults 18-50 years old from the United Arab Emirates. Metab Syndr Relat Disord 2010;8:39-46.

Al-Shafaee MA, Ganguly SS, Bhargava K, Duttagupta KK. Prevalence of metabolic syndrome among prediabetic Omani adults: a preliminary study. Metab Syndr Relat Disord 2008;6:275-279.

Al-Thani MH, Al-Thani AA, Cheema S, Sheikh J, Mamtani R, Lowenfels AB, Al-Chetachi WF, Almalki BA, Hassan Khalifa SA, Haj Bakri AO, Maisonneuve P. Prevalence and determinants of metabolic syndrome in Qatar: results from a National Health Survey. BMJ Open 2016;6: e009514.

Al Zenki S, Al Omirah H, Al Hooti S, Al Hamad N, Jackson RT, Rao A, Al Jahmah N, Al Obaid I, Al Ghanim J, Al Somaie M, Zaghloul S, Al Othman A. High prevalence of metabolic syndrome among Kuwaiti adults-a wake-up call for public health intervention. Int J Environ Res Public Health 2012;9:1984-1996.

Aljabri KS, Bokhari SA, Alshareef MA, Khan PM. Prevalence of the metabolic syndrome in the Saudi population. Arch Diabetes Obes 2018a;1: 45-53.

Aljabri KS, Bokhari SA, Alshareef MA, Khan PM, Aljabri BK. Prevalence of metabolic syndrome in obese Saudi population. Interv Obes Diabetes 2018b;2:1-7.

Aljohani NJ. Metabolic syndrome: risk factors among adults in Kingdom of Saudi Arabia. J Family Community Med 2014;21:170-175.

Alswat MK, Alnemar AK, Alghamdi I, Al-thomali B, Mahfouz T, Althobaiti SM, Alshehri AA. Prevalence of metabolic syndrome in hospitalized patients with psychiatric illness in Taif city, Saudi Arabia. Endocr Pract 2016;22:118-119.

Alzahrani AM, Karawagh AM, Alshahrani FM, Naser TA, Ahmed AA, Alsharef EH. Prevalence and predictors of metabolic syndrome among healthy Saudi Adults. Br J Diabetes Vasc Dis 2012;12:78-80.

Alzeidan RA, Rabiee F, Mandil AA, Hersi AS, Ullah AA. Changes in dietary habits, physical activity and status of metabolic syndrome among expatriates in Saudi Arabia. East Mediterr Health J 2018;23:836-844.

Badr HE, Al Orifan F, Amasha M, Khadadah KE, Younis HH, Se'adah M. Prevalence of metabolic syndrome among healthy Kuwaiti adults: Primary health care centers based study. Middle East J Family Med 2007;5:30-36.

Bahijri SM, Al Raddadi RM, Jambi H, Alaama MNA, Ferns G. The prevalence of metabolic syndrome in an apparently healthy, normotensive and non-diabetic population in Saudi Arabia by two definitions: implications for local practice. Open J Endocr Metab Dis 2013;3:18-24.

Barrimah I, Al Muhaimeed AR, Shobaily HA, Midhet F. Prevalence of metabolic syndrome among Qassim University personnel in Saudi Arabia. Int J Health Sci (Qassim) 2011;5(2 Suppl 1):49-50.

Bener A, Darwish S, Al-Hamaq AO, Yousafzai MT, Nasralla EA. The potential impact of family history of metabolic syndrome and risk of type 2 diabetes mellitus: In a highly endogamous population. Indian J Endocrinol Metab 2014;18:202-209.

Bener A, Zirie M, Musallam M, Khader YS, Al-Hamaq AO. Prevalence of metabolic syndrome according to Adult Treatment Panel III and International Diabetes Federation criteria: a population-based study. Metab Syndr Relat Disord 2009;7:221-229.

Boodai SA, Cherry LM, Sattar NA, Reilly JJ. Prevalence of cardiometabolic risk factors and metabolic syndrome in obese Kuwaiti adolescents. Diabetes Metab Syndr Obes 2014;7:505-511.

El-Aty MA, Mabry R, Morsi M, Al-Lawati J, Al-Riyami A, El-Sayed M. Metabolic syndrome and its components: secondary analysis of the World Health Survey, Oman. Sultan Qaboos Univ Med J 2014;14: e460-e467.

Fezeu L, Balkau B, Kengne AP, Sobngwi E, Mbanya JC. Metabolic syndrome in a sub-Saharan African setting: central obesity may be the key determinant. Atherosclerosis 2007;193:70-76.

Ford ES. Prevalence of the metabolic syndrome defined by the International Diabetes Federation among adults in the U.S. Diabetes Care 2005;28:2745-2749.

Hajat C, Shather Z. Prevalence of metabolic syndrome and prediction of diabetes using IDF versus ATPIII criteria in a Middle East population. Diabetes Res Clin Pract 2012;98:481-486.

Hammoudeh S, Ghuloum S, Mahfoud Z, Yehya A, Abdulhakam A, AlMujalli A, Al-Zirie M, Abdel Rahman MO, Godwin A, Younes N, Hani Y, Mook-Kanamori D, Mook-Kanamori M, El Sherbiny R, AlAmin $\mathrm{H}$. The prevalence of metabolic syndrome in patients receiving antipsychotics in Qatar: a cross sectional comparative study. BMC Psychiatry 2018;18:81.

Haroun D, Mechli R, Sahuri R, AlKhatib S, Obeid O, El Mallah C, Wood L, AlSuwaidi K. Metabolic syndrome among adolescents in Dubai, United Arab Emirates, is attributable to the high prevalence of low HDL levels: a cross-sectional study. BMC Public Health 2018;18:1284.

Hu G, Qiao Q, Tuomilehto J, Balkau B, Borch-Johnsen K, Pyorala K; DECODE Study Group. Prevalence of the metabolic syndrome and its relation to all-cause and cardiovascular mortality in nondiabetic European men and women. Arch Intern Med 2004;164:1066-1076.

Huang PL. A comprehensive definition for metabolic syndrome. Dis Model Mech 2009;2:231-237.

Kamran S, Bener AB, Deleu D, Khoja W, Jumma M, Al Shubali A, Inshashi J, Sharouqi I, Al Khabouri J. The level of awareness of stroke risk factors and symptoms in the Gulf Cooperation Council countries: Gulf 
Cooperation Council stroke awareness study. Neuroepidemiology 2007;292:235-242.

Khthir R, Espina FL. The metabolic syndrome in rural UAE: the effect of gender, ethnicity and the environment in its prevalence. J Metab Syndr 2014;3:159.

Malik M, Razig SA. The prevalence of the metabolic syndrome among the multiethnic population of the United Arab Emirates: a report of a national survey. Metab Syndr Relat Disord 2008;6:177-186.

Márquez-Sandoval F, Macedo-Ojeda G, Viramontes-Hörner D, Fernández Ballart JD, Salas Salvadó J, Vizmanos B. The prevalence of metabolic syndrome in Latin America: a systematic review. Public Health Nutr 2011;14:1702-1713.

Mente A, Yusuf S, Islam S, McQueen MJ, Tanomsup S, Onen CL, Rangarajan S, Gerstein HC, Anand SS; INTERHEART Investigators. Metabolic syndrome and risk of acute myocardial infarction a case-control study of 26,903 subjects from 52 countries. J Am Coll Cardiol 2010;55: 2390-2398.

Moher D, Liberati A, Tetzlaff J, Altman DG; PRISMA Group. Preferred reporting items for systematic reviews and meta-analyses: the PRISMA statement. Int J Surg 2010;8:336-341.
Ranasinghe P, Mathangasinghe Y, Jayawardena R, Hills AP, Misra A. Prevalence and trends of metabolic syndrome among adults in the asia-pacific region: a systematic review. BMC Public Health 2017; 17:101.

Roshdy R. Prevalence of metabolic syndrome in patients with schizophrenia. Middle East Curr Psychiatry 2011;18:109-117.

Rouzi A, Ardawi M. Prevalence of the metabolic syndrome in Saudi women and its components with polycystic ovary syndrome. Maturitas 2009;63(Supplement 1):S132.

Saeed AA. Prevalence of metabolic syndrome and its components among Saudi young adults 18-30 years of age. Open J Endocr Metab Dis 2019;9:49-59.

Shamseer L, Moher D, Clarke M, Ghersi D, Liberati A, Petticrew M, Shekelle P, Stewart LA; PRISMA-P Group. Preferred reporting items for systematic review and meta-analysis protocols (PRISMA-P) 2015: elaboration and explanation. BMJ 2015;350:g7647.

Taha D, Ahmed O, bin Sadiq B. The prevalence of metabolic syndrome and cardiovascular risk factors in a group of obese Saudi children and adolescents: a hospital-based study. Ann Saudi Med 2009;29:357-360. 